\title{
Effectivity of a joint didactic intervention by school for patients on inappropriate control prothrombin time anticoagulated patients
}

\author{
Ginel Mendoza $L^{*}$ and Hidalgo Natera $A$ \\ Centro de Salud Ciudad Jardín, Distrito Sanitario Málaga-Guadalhorce, C/ Sancho Miranda 9, Málaga, Spain
}

Oral anticoagulant drugs represent an essential tool in thromboembolic events prevention particularly in patients suffering from atrial fibrillation or heart prosthetic valve wearers. Most used are vitamin $\mathrm{K}$ antagonists (VKA), whose plasma level is monitored by measuring prothrombin time using the International Normalized Ratio (INR).

If it takes values out of the recommended range, the patient will have a higher risk of suffering from thromboembolic or haemorrhagic complications. These are relevant reasons to carry out preventive actions.

Another option to solve this problem could be to replace VKA by non-vitamin $\mathrm{K}$ antagonist oral anticoagulants (NOACs). However, these drugs have no approved use in heart prosthetic valve wearers and besides that, many unresolved questions on how to optimally use these agents in specific clinical situations remain.

Copyright: (2) 2019 Mendoza GL. This is an open-access article distributed under the terms of the Creative Commons Attribution License, which permits unrestricted use, distribution, and reproduction in any medium, provided the original author and source are credited.
Previous research has shown that about $33 \%$ of total VKA anticoagulated patients keep values on inappropriate level.

Through educational and behavioural interventions, these patients increase their knowledge and understanding of the action mechanisms of anticoagulants drugs which may increase their ability to keep an INR appropriate control.

Selfcare support programs are presented as a tool to accomplish a change. This tool or method is also presented as an alternative to the one in which citizens could receive more information about their health state (this fact is in accordance with a demonstrated rise in people's request on health issues via the internet).

The present study shows that conducting an organized group educational intervention on VKA anticoagulated patients by using the School for Patients method will result in improved inappropriate INR control levels.
*Correspondence to: Leovigildo Ginel Mendoza, Centro de Salud Ciudad Jardín, Distrito Sanitario Málaga-Guadalhorce, C/ Sancho Miranda 9, 29014, Málaga, Spain, E-mail: lginel@gmail.com

Received: August 17, 2019; Accepted: August 27, 2019; Published: August 29, 2019 